\title{
Games for organizational learning in production management
}

\author{
J. O. Riis, R. Smeds, J. Johansen, H. Mikkelsen
}

Dept. of Production, Aalborg University, Fibigerstraede 16, DK-9220 Aalborg, Denmark

Dept. of Industrial Management, Helsinki University of Technology, Otakaari 8, SF-02150 Espoo, Finland Dept. of International Marketing and Management, Southern Business School, Grundtvigs Alle 150, DK-6400 Sфnderborg, Denmark

Sant \& Bendix Consulting, Skovlytoften 9B, DK-2840 Holte, Denmark

E-mail: i9jor@iprod.auc.dk

\begin{abstract}
Development and implementation of new production management methods and systems represents a challenge to the individual employee, manager, student or teacher. Understanding dynamic and complex systems is very difficult, old methods and working habits have to be unlearned, a new kind of knowledge is required, and it is important to acquire proficiency in doing.

The paper will discuss these issues and outlines the role which games of various kind may play in this respect. Among other things, the use of games provides a setting in which experimentation is stimulated without the risk of loosing face. Finally, the use of games will be tied to the concept of organizational learning.
\end{abstract}

\section{Keywords}

The dynamic nature of production management; Simulation games; Organizational learning; Capability for rapid change. 


\section{CHALLENGES TO PRODUCTION MANAGEMENT}

Industrial enterprises are increasingly challenged by the market situation and the advancement of technology to improve their capability for implementing speedy and substantial changes in their operation, including production management, plant layout, production processes and organization.

Three challenges are particularly important

1. Rate of change. The rate of changes imposed on an industrial enterprise is increasing which calls for a greater proficiency in adopting new methods and systems and in implementing them with high precision. In addition, the rate of change demands better ways of learning from past experience and of adopting new knowledge.

2. Integration. The need to integrate different disciplines and perspectives across traditional organizational boundaries in order to exploit the potential synergy, e.g. to link production management to product design and production engineering, and to suppliers and customers in the logistic chain.

3. Involvement of employees. A greater involvement of employees to take an active part not only in the operation but also in the development of industrial enterprises. Terms like autonomy, empowerment, and collaborative working modes indicate the direction of this effort.

These challenges are in contrast with the current situation in many industrial enterprises which may be characterized by (1) a dominating focus on the day-to-day operation and routines aimed at securing delivery on time, quality and cost effectiveness - with little concern for continuous improvement; (2) management systems which are unable to support learning processes, such as collecting and retrieving past decisions and extracting experience and lessons learned; (3) a tradition for perceiving a change as a rational, deterministic decision process, rather than as a series of experiments; sometimes experiments are even considered risky by individual employees to indulge in.

Also teachers of production management are affected by the challenges to industrial enterprises; conveying the complex and dynamic nature of production management has become a significant challenge. At the same time a quest for increased productivity in teaching is imposed. Important issues are questioned, such as the role of teachers (instructors, coach or facilitators) and the goal of education (knowledge versus proficiency and capability).

This paper will address these challenges by discussing one approach, which by far is not the only one, to meet these challenges, namely that of using games at universities and in industry to stimulate learning processes in connection with development and implementation of new production management systems and methods. However, we need to better understand the context and processes of implementation. Therefore, we shall first point to behavioural issues of implementation. This will provide a basis for delineating different roles which simulation 
games may plan in facilitating change. We shall also discuss experiences from using games for implementing changes. Finally, the scope will be widened to include a more general discussion of organizational learning.

The signifance of the paper thus is (1) an identification of essential behavioural issues of implementing change; (2) a discussion of different roles which simulation games may play, and experiences gathererd; and (3) a relationship established between simulation games and organizational learning.

\section{BEHAVIOURAL ASPECTS}

In the following we shall outline some of the issues associated with development and implementation of production management systems and methods, seen from an individual, behavioural perspective.

Understanding dynamic and complex systems is difficult. A dynamic system with delays and many interacting parts and relationships easily becomes difficult to comprehend, even when relevant information is available, cf. Senge (1990). In an enterprise, employees and managers are interacting. Their decisions are often made independently, but are mutually interdependent. Therefore, an individual employee or manager usually has only limited information of the various elements of the system, and the decisions made based on this confined knowledge even increase the dynamic complexity of the system.

A typical reaction on part of an employee or student, confronted with a dynamic and complex situation, is uncertainty and fear of the unknown, bewilderment, disenchantment and de-motivation. Not understanding the dynamic nature of a system thus may be counter-productive to an effort to involve employees more actively.

Unlearning is often the first step of learning new methods and working modes. An employee or manager in an industrial enterprise involved in production management will have learned to operate the current production management system. Often the know-how has been acquired through on-the-job training and many years of experience. Thus, if new methods and systems are to be introduced, the persons involved will necessarily have to unlearn the old methods and working modes.

Also students may need to unlearn, even if they are confronted with production management for the first time. Their prior education may have given them the conviction, for example based on basic courses in physics, that everything may be quantified, and that there is always one correct solution. Furthermore, a student may have acquired the point of view that any problem may be completely described by adopting only a single person's view and just one perspective.

To unlearn may be a difficult process. When we analyzed the reluctance of a group of production planners to question their present mode of working, it turned out, that many of them had worked with the MRP system during most of their pro- 
fessional careers, without having understood the system completely. But they had learned to operate the system to some degree of success. They had to be convinced, that alternative methods existed and would do a better job. Unlearning may not be successful unless the employees or managers have gained concrete experience in operating new systems or methods.

Knowledge is still important, but which kind of knowledge? A thorough knowledge is still of prime value when developing and implementing production management systems and methods, whether it be general knowledge of planning principles and available software systems or specific knowledge of the operation and behaviour of a given system in a particular company situation. However, much knowledge presented to students is at the level of "heard of" or "knowof". Little emphasis is placed on providing students with a "know-how" level of proficiency enabling them to apply appropriate methods and systems to specific situations.

The knowledge of graduates is compartmentalized into well defined clusters or disciplines with no capability to identify and use connecting relationships. The challenges to production management presented in the first section of this paper give rise to ask, if our conception of the knowledge an engineering graduate needs to possess should not be changed accordingly, e.g. to include knowledge of how to identify the mutual interdependencies between persons and organizational units in production management, or knowledge of how to integrate different disciplines and perspectives.

Individual proficiency in doing, and organizational capability. Learning production management systems and methods as an individual skill may be compared with learning to ride a bicycle, or learning to play the violin. A certain portion of intellectual effort is needed to understand the basic operation of a bicycle, but the real proficiency comes from practicing. This may be facilitated in various ways, e.g. by two smaller wheels fixed at either side, or by the father running behind ready to support. A textbook on bicycles may have a long chapter on how to keep the balance. Nevertheless, nobody would ever be able to ride a bicycle just on the basis of having read the textbook.

But proficiency is not only the individual mastering of a skill. Human activity is basically social. The cyclist has to be able to ride with others in the traffic to get to his destination. The violinist plays with an ensemble to reach a common musical vision, and improves in this interaction also the personal mastery of the instrument. Sharing experiences is essential for learning in human systems in general, and especially in the learning of goal-directed teams and organizations, cf. Nonaka and Takeuchi (1995).

Thus, production management systems and methods can only be learned, if also practiced within an organizational context. It should be of no surprise that young graduates experience a shock when they are asked in their job to transform their knowledge into practice. In enterprises, we can also observe a lack of shared expe- 
riences in the many futile discussions between those who have knowledge, but no experience in doing, and those with practical know-how, but no understanding and insight. This becomes evident especially in change situations, where management spends much effort in telling employees about future changes, but with no attempt to let them experience elements of the new system in advance to provide some hand-on insight. The result is often resistance to change.

Experimenting without loosing face. Among engineers and managers there exists a widely accepted notion that it is part of the professional job to show decisiveness and to signal to the rest of the organization that no doubt exists. With the increased complexity and turbulence in production management, it has however become increasingly difficult to maintain the image of having everything under control.

Much is at stake for an employee, student as well as a manager when a new working mode is to be adopted. For natural reasons, the individual may have no prior experience and may be nervous to show to others that he or she is not fully competent. The individual may be afraid of loosing face, if unsuccessful.

Admitting the existence of uncertainties and adopting shared experimentation as an explicit instrument for learning could offer a new potential to manage change processes. Hence, it is important to carry out a change process in such a way that experimentation and play is encouraged. The opportunity to try out new methods should be protected from serious consequences, and mistakes should be considered as part of the learning process.

Experimenting with prototypes throughout the innovation process is common practice in product development projects. Also for process innovations, the "prototyping" of new process designs in teams accelerates the innovation process and leads to better solutions, cf. Smeds (1994).

\section{THE ROLE OF SIMKULATION GAMES}

\subsection{Common Experience creates Shared Perception}

Simulation games may be defined as a dynamic simulation of reality during which the participants (players) act, e.g. make decisions or produce. The actions taken by players affect the following situation confronting the players. Games can in principle be played alone (e.g. against a computer) or with a group, but only in the latter case, a shared experience for learning is created.

A large variety of different games has been used in the area of production management, in industrial enterprises as well as in universities, spanning from a simple, one-hour JIT game demonstrating the difference between a push and a pull system to an elaborate, several-days computer-assisted MRP-game which trains players in using MRP for a number of situations, cf. Riis et al. (1993). Also 
enterprise specific games for business process development have been used, cf. Smeds (1994), Smeds and Haho (1995), Mikkelsen et al. (1990), Riis (1996).

In a production system game, the participants experiment and discuss the dynamic relationships between activities. They can experience the consequences of differentiated task structures, the unnecessary complexity in information and material flow, of rules and systems, and the need and possibilities for improved, processoriented co-operation and communication. Sharing these experiences in the game creates the shared mental models and technical skills, that enable team members to understand their task, and to coordinate and develop them adapting their behaviour to the demands of the process and of the team members.

\subsection{Many Aspects treated}

The production system games bridge inter-departmental boundaries and give the opportunity for a process-oriented, holistic view. The games are capable of dealing with many different aspects connected to production, such as marketing (with an increased awareness of external threats and need for improving competitiveness), sales (with a recognition of the importance of demand variety), product development and engineering design (with an appreciation of the uncertainties of the development process), purchasing (with an insight into the conditions for vendors and subcontractors), etc.

If managers and employees participate in the game, the interlevel dialogue between strategy and operation can even enable the recognition and development of new strategic capabilities.

\subsection{Transfer from Game to Reality}

Games are only models of reality. The more abstract and detached from a specific enterprise situation or from the players' experience they are, the more time-outs during the game, as well as separate debriefing periods following each run of a game are needed to discuss and relate the game experiences and observations to the players' own situation.

A game provides a setting in which it is costless to experiment and to make errors. Experimentation is encouraged, e.g. new ideas of planning and new planning concepts may be tried out with the effect that players experience by all their senses what the new solution might imply, without fear of criticism of own personality or capabilities. The players can also experiment with different roles, and conflicts can be used as learning instruments to intensify the shared experience. 


\section{GAMES IN CHANGE MANAGEMENT}

\subsection{Empowerment as Basic Principle}

An underlying assumption behind using games in organizational changes is that participation is instrumental for the success of the change process. Through participation in the change process, a common understanding and commitment to change is created, more viable ideas are developed, and their implementation into innovations is facilitated, cf. Moss Kanter (1983), Zuboff (1991), Smeds (1996). The jointly developed solutions are likely to be better both in productivity and work satisfaction, and resistance to change can be avoided to a great extent, cf. Cotton et al. (1988).

Thus, the games for production system redesign should be built based on the basic principle of empowerment. In several enterprises, we have developed company specific games which allow the employees to identify their own job in the game, and to easily transfer the conclusions of the game to their own situation, cf. Smeds (1994), Smeds and Haho (1995), Mikkelsen et al. (1990), Riis (1996).

\subsection{Games can be used in all Change Phases}

Games can support all phases of a change process, respectively (1) the initial phase; (2) the design phase; and (3) the realization phase. They can also be used later for training and continuous improvement of the new design.

1. The initial phase. Simulation games can create for all involved a common understanding of the present situation, and an awareness and need for change. Unsatisfactory performance, e.g. in terms of poor precision in deliveries and quality, is often caused by the complex interplay of many sections and departments, which can be jointly experienced and discussed in the game.

The game generates immediately many improvement ideas. To direct the change process, chosen production management principles and specific change objectives can be used as a guideline for the ideas, and later during debriefing and design.

2. The design phase. Some generic games offer the opportunity to try out several production management principles and different planning methods, which provide a good background for a large group of employees in a company to select a basic solution which they feel comfortable with.

The company specific games support the design phase in a prototyping manner. Following the general objectives of the change process, a separate development team converts the ideas of the initial game into a possible new process design, which is then simulated in a proceeding game. With consecutive rounds of development work and games, analysis and synthesis, a satisfactory design is created with a high degree of empowerment. Thus, a significant step towards implementa- 
tion is already taken in the shared mental models of the participants, before the actual realization starts, cf. Smeds (1994).

3. The realization phase. An important activity is training of the employees who are to operate the new system. Games may not only provide a thorough understanding of the functioning of the new system, but also give hands-on experience in operating the system under various conditions.

When the new production system is running, incremental innovations are very likely to develop, and to be of high quality, since all employees in the process have participated in the games and thus possess the holistic understanding of the whole process. After the incremental improvements have reached their limits, the need for a new major reorganization is perceived, and the development spiral is repeated.

Management needs feedback and communication about the progress of change, and the employees need the feedback to preserve their motivation and learning during realization and stabilization of the new process design. The same guidelines and measures that were used to evaluate the different simulated designs can also be used as feedback indicators during realization, everyday operation, and continuous improvement. They should if possible be converted into visual milestones, to give the whole organization the possibility to learn from examples, cf. Riis (1990).

\subsection{Precautions}

A risk of using games for stimulating a change process is that players are not able to relate the experiences to their company and to their own job situation. At worst the game would only be considered a waste of time or a period of fun with no transfer effect. Thus, the choice of game is critical. This explains our effort to develop company-specific games.

The cost of running a game should be considered, especially the time in which the players are away from their job. This has led us to focus attention on limiting the duration of a game, typically from a three-day session to just one day.

\section{LEARNING IN INDUSTRIAL ORGANIZATIONS}

According to Nonaka and Takeuchi (1995), organizational learning is a dynamic conversion process between tacit and explicit knowledge into a spiral of knowledge creation. (Figure 1) 


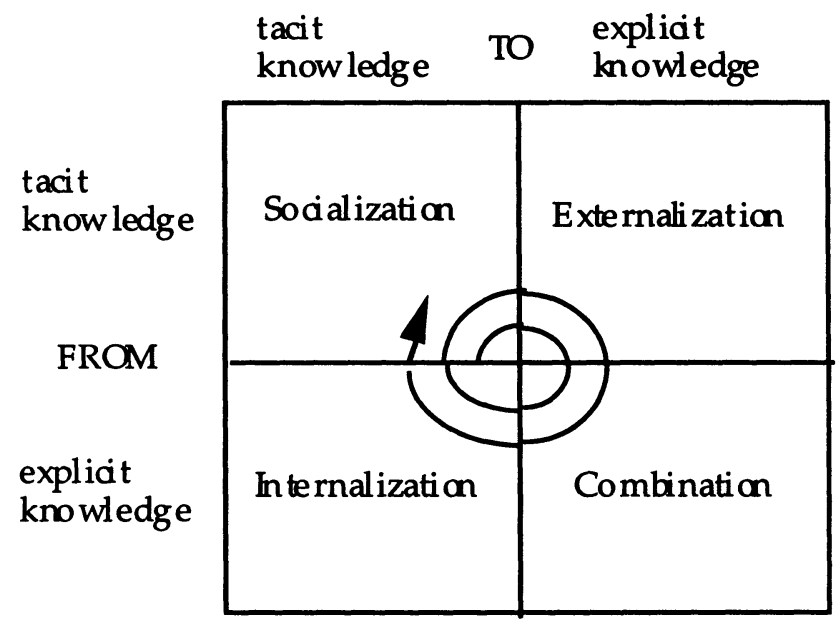

Figure 1 The four modes of knowledge conversion and the knowledge spiral.

Simulation games support all steps in the knowledge conversion process where tacit knowledge is involved: Socialization (sharing the individual, tacit knowledge through the joint game experience, resulting in shared mental models and technical skills); Externalization (making tacit knowledge explicit through conceptualization and dialogue in the game and in the debriefings); and Internalization (experimenting alternative designs in games, learning by doing, and adopting the new mode of working into use, which means the conversion from explicit back to tacit individual knowledge). The Combination of different bodies of explicit knowledge into a new design is typically not conducted in the games, but in debriefings or separate design teams.

Thus the games are one method to catalyze the crucial dialogue for learning between the individuals' proficiency and the organization's capability. Games create a temporary structure for learning and innovation on both individual and organizational level. The game team is like an orchestra that rehearses the music together to bring it to the shared vision. If top management participates in the game, a strategic innovation, a new "composition", may emerge in the experimental dialogue between strategy and operation.

The formal management systems, e.g. production management systems, have a great influence on the collective learning processes. Therefore, it is important to understand their role and interplay between individual informal learning, as discussed in Neergaard (1994).

The authors are of the opinion that simulation games are an important method for creating the organizational learning spiral for the continuous development of industrial enterprises. In addition, and perhaps even more importantly, by applying 
games in the development of production systems, an increased understanding of organizational learning in industrial enterprises may also emerge.

\section{CONCLUSION}

In this paper we have addressed the challenges confronting industrial enterprises of speedy adoption of new methods and systems for production management. In view of its dynamic and complex nature this is a difficult task. Also teachers of production management are affected by these challenges.

To be effective in developing and implementing new methods and systems it is necessary to understand the individual employee, manager, student or teacher. In section 2 we discussed that an individual or a group often is unwilling to adopt new methods and working modes, before the old methods and habits have been unlearned. Furthermore, the proficiency of doing and not just knowing was stressed, like learning to ride a bicycle or play an instrument in an orchestra. In view of the complex nature and the lack of knowledge we argued that it was important to create a setting in which experimentation is possible without loosing face.

One way of dealing with some of these issues is to use games of various kind in different situations. Section 3 and 4 summarized what games may do in connection with training new proficiencies and with organizational changes. Among other things it was argued that games provides a common experience which creates shared perceptions. Furthermore, it was demonstrated that games may be used in all phases of an organizational change process. In the last section the paper related games to selected aspects of organizational learning with particular focus on the transformation of individual tacit knowledge to explicit, collective knowledge. Also it was stated that an increased understanding of organizational learning may emerge by applying games.

\section{REFERENCES}

Cotton, J.L., Vollrath, D.A., Froggatt, K.L., Lenginck-Hall, M.L., Jennings, K.R. (1988): Employee Participation: Diverse Forms and Different Outcomes, Academy of Management Review, Vol. 13, No 1, pp. 8-22.

Mikkelsen, Hans, Lars Mitens and Jens O. Riis (1990): Simple, company-specific games for developing production management (in Danish), Aalborg University Press.

Moss Kanter, Rosabeth (1983): The Change Masters. Innovation and Entrepreneurship in the American Corporation. Simon \& Schuster, Inc., New York.

Neergaard, Claus, 1994: Creating a Learning Organisation - A Comprehensive Framework, Ph. D. dissertation, Dept. of Production, Aalborg University, Denmark. 
Nonaka, Ikujiro and Takeuchi, Hirotaka (1995): The Knowledge Creating Company, Oxford University Press, Oxford.

Riis, Jens O. (1990): The use of production management concepts in the design of production management systems, Production Planning and Control, 1990, Vol 1, No. 1, 45-52.

Riis, Jens O., John Johansen and Hans Mikkelsen, (1993): Games in Production Management, p. 209-216 in Advances in Production Management Systems, IFIP Transactions B-13, North-Holland.

Riis, Jens O. (1996): Games for implementing changes in industrial enterprises, p. 72 - 84 in The Simulation and Gaming Yearbook Volume 4 - Games and Simulations to Enhance Quality Learning, Edited by Danny Saunders, Fred Percival and Matti Vartiainen, Kogan Page

Senge, Peter M. (1990): The Fifth Discipline. The Art \& Practice of the Learning Organization, Doubleday, New York.

Smeds, Riitta (1994): Managing Change Towards Lean Enterprises. International Journal of Operations and Production Management, Vol. 14/3, pp. 66-82.

Smeds, Riitta (1996): Successful Transformation: Strategic evolution management for competitive advantage, Business Change and Re-engineering. The Journal of Corporate Transformation, Vol. 3, No 2, 62-72

Smeds, Riitta and Haho, Päivi (1995): Tailored order-to-delivery process game, in J. Riis (Ed.) Simulation Games and Learning in Production Management, Chapman \& Hall, London, 145-155.

Zuboff, Shoshana (1991): Address in the debate: Can Research Reinvent the Corporation? Harvard Business Review, March-April, pp. 164-165.

\section{BIOGRAPHICAL NOTE}

Jens O. Riis is a Professor of Industrial Management Systems at the Department of Production, Aalborg University, Denmark. He holds an M.Sc. in Mechanical Engineering from the Technical University of Denmark and a Ph.D. in Operations Research from the University of Pennsylvania, USA. His main teaching and research areas are design of production management systems, technology management, project management, and integrated production systems. He worked with John L. Burbidge in the late 80's on integration in manufacturing and exchanged on many occasions ideas and experiences about forming production groups. Prof. Riis is currently heading two research programs in integrated production systems and technology management, and is a member of the IFIP Working Group 5.7 on Computer Aided Production Management Systems and of the international editorial board of several international journals.

Riitta Smeds is the head of the new Enterprise Simulation Laboratory at Helsinki University of Technology, TAI-Reserach Centre. She has acted a associate 
professor and lecturer of Industrial Management at HUT, and acts currently as professor at the Swedish School of Economics and Business Administration, Department of Management and Organization. Riitta Smeds holds a M.Sc., a Lic.Tech. and a D. Tech in Industrial Management from HUT. She is a member of the International Foundation for Production Research IFPR, of the European Group for Organizational Studies EGOS, and of IFIP Working Group 5.7 on Computer Aided Production Management Systems. She is also a member of the editorial board of "Knowledge and Process Management, The Journal of Corporate Transformation". Her main research areas are enterprise evolution, management of technology and innovation, organizational learning and change, business process reengineering, and enterprise simulation methods.

John Johansen is a professor of Industrial Management at the Department of International Marketing and Management, Southern Denmark Business School. He holds an M.Sc. in Engineering and a Ph.D. in Industrial Management from the Aalborg University. His main area of teaching and research are Production Management, Production and Material Control, and Supply Chain Management. Professor John Johansen is a member of the IFIP Working Group 5.7 on Computer Aided Production Management Systems.

Hans Mikkelsen is a Senior Consultant at Sant + Bendix, a member of Coopers \& Lybrand. He holds an M.Sc. in Mechanical Engineering from the Technical University of Denmark and has been involved in consultant work and development projects in the areas of design of production system, production management systems, project management and product development both from a system's perspective and from an organizational and management point of view. 